\title{
An Empirical Survey of Young Peasant Workers' Leisure Life Situation and the Correlation Study of Moral Relationships in Hefei in Anhui Province
}

\author{
Teng Han, Dong Xunjuan \\ School of Humanities and Social Sciences, Anhui Agricultural University, Hefei, China \\ Email address: \\ 695481545@qq.com (Teng Han), 1723612226@qq.com (Dong Xunjuan) \\ To cite this article: \\ Teng Han, Dong Xunjuan. An Empirical Survey of Young Peasant Workers' Leisure Life Situation and the Correlation Study of Moral \\ Relationships in Hefei in Anhui Province. Social Sciences. Vol. 6, No. 6, 2017, pp. 209-213. doi: 10.11648/j.ss.20170606.19
}

Received: October 14, 2017; Accepted: November 9, 2017; Published: December 20, 2017

\begin{abstract}
This paper centers on leisure life situation and the moral interpersonal behavior of 276 young peasant workers who live in Hefei in Anhui province using the methods of questionnaires and interviews. The results indicate that young peasant workers' leisure time has a significant negative correlation with immoral relationship and is significantly positive correlated with excellent moral relationship. Besides, fitness and reading are positively associated with love, tolerance and other excellent moral relationship in leisure life and have a significant negative correlation with fraud as well as others which belong to bad moral interpersonal relationship. However, there is a significantly negative correlation between travel and responsibility and positive correlation with mutual utilization. At the same time, the author comes up with some specific recommendations which improve the immoral relationships of young migrant workers according to the research results.
\end{abstract}

Keywords: Young Peasant Workers, Leisure Life Situation, Moral Relationships

\section{Introduction}

The migrant workers mostly consist of young peasant workers in our country. According to the statistics, the young migrant workers, nearly 150 million people, have become the mainstream of more than two hundred million migrant workers group. The moral interpersonal relationship, being one of the important part of relations, it reflects the young migrant workers' harmonious degree of interpersonal relationship, also reflects their inner moral quality. There is no doubt that young peasant workers' moral relationships make a great significance in maintaining their mental health and the harmony of city. Ample evidence shows that the value and significance of moral health in mental health (Pan, 2010). In the current years, young peasant workers' physical and mental health and living quality become increasingly prominent, it has a practical significance to study moral relationship of young migrant workers and deliver them moral education.

However, due to the characteristics of young migrant workers in work life, it is difficult and ineffective for them to carry out moral education intensely. The subject, inevitably, which focuses on how to deal with the particularity of young peasant workers' moral indoctrination and use appropriate methods to educate them, is with regard to the current young peasant workers' moral quality promoting, morality interpersonal relationship improving and maintaining mental health. According to this, the author thinks it is a feasible method that choosing the leisure life of young migrant workers in a diffuse and penetrative moral education. Then you need to study the association between young peasant workers' leisure life and moral relationship, and find what kind of leisure life is close to moral relationship, so that the government specifically carries out the young peasant workers' leisure life and improves their moral relationship.

There is under-researched on the leisure life conditions of Chinese young peasant workers at present, even lack of research on the relations between their leisure life conditions and moral interpersonal situation. Among the scanty literatures, for example, Ma Chunhong (2007) deliberated the crime space behind leisure life problematization which is based on the perspective of cultural conflict; Li Guicheng, Liang Lin (2014) studied existential issues of young peasant workers' leisure life and put forward the corresponding countermeasures taking peasants of Zheng Zhou in He Nan as 
a example by questionnaire and interview; Ye ling, Guan Lingli, Zhou Xiaozhu proposed young peasant workers' leisure life education from different perspectives. However, people need to carry on exploratory thinking and research on young peasant workers' leisure life as well as the conditions and the moral relationships. This study investigates into the contemporary Chinese young peasant workers' leisure life conditions and their moral interrelationships. Besides, the research focuses on the relationship of them.

\section{Research Methods}

\subsection{Respondents}

The respondents are young migrant workers in Hefei in Anhui province, specific sampling methods are questionnaire survey and follow-up interviews on 276 young migrant workers in Hefei using stratified random sampling among the 153 men and 123 women in the study, whose age is between 23-29.

\subsection{Research Tools}

A questionnaire for the investigation of the self tools, according to the existing research results and preliminary experts consultation, the questionnaire which mainly borrows from "leisure life" and "moral relationships" design in "the survey on humanity quality of Chinese citizen" (Shi et al, 2009) finally is designed two questions considering the particularity of the young farmers.

Item one is: "which do you prefer to do in your spare time in the following three things?" The answer options are: (1) fitness, sports; (2) reading; (3) tourism; (4) drink; (5) watching television; (6) karaoke, bubble; (7) gambling (including mahjong, playing cards); (8) mahjong, playing chess (except gambling); (9) art appreciation; (10) continuing to work or earn money. The requirement is that people are supposed to choose three answers in the ten options.

Item 2 is "do you think which actually three kinds of qualities or interrelationships are the most for human present?" The answer options are: (1) care (help); (2) indifference (diaphragm); (3) tolerance; (4) irresponsibility; (5) fraud; (6) responsibility; (7) hostility; (8) integrity; (9) inter-availability; (10) communication (understanding). The respondents must choose three answers in ten options. Two questions reflect a tendency that for each option, if they choose, they will get one point, on the contrary, they have no point. And there are no right and wrong answers. The application is SPSS 16.0 data processing systems.

\section{Results and Analysis}

\subsection{Young Peasant Workers' Leisure Life Types}

Young migrant workers tend to choose their leisure life types from high to low in turn are watching $\mathrm{TV}$, reading, fitness, travel, art appreciation, chess entertainment, Internet cafes, or karaoke, drink, working, gambling.

Table 1 is distribution of visitors and the related ranks of young peasant workers' leisure life type. From it, it's apparent that 276 young migrant workers prefer to choose "watching TV", the followings are "reading", "fitness", "travel", "art appreciation", "chess entertainment", "Internet cafes or karaoke", "drink" "working", "gambling".

Among the leisure life of 276 young peasant workers, "Watching TV" is the most common leisure life style after work, 167 people claim that "watching TV" is the main way of leisure in their daily life. There are 154 young migrant workers who choose reading as a way of relaxation, interviews reveal that they read via some paper which put on the wall or sold in the kiosk. Besides, the way of reading is limited and the reading environment is full of instability. Choosing "fitness" as their main leisure lifestyle is 136 people, selecting "tourism" is 125 people, choosing "art appreciation is 69 people. Then, 52 young peasant workers prefer chess entertainment, 43 of them are fond of Internet cafes or karaoke, 37 people choose not to relax but to work, 26 of them tend to drink and 19 of them choose "gambling". In general, their ways of leisure life focus on "watching TV" "reading" "fitness", "travel" or "art appreciation" among 276 young peasant workers.

Table 1. Distribution of visitors and ranks of young peasant workers' leisure life $(N=276)$.

\begin{tabular}{|c|c|c|c|c|c|}
\hline & Watching TV & reading & fitness & tourism & art appreciation \\
\hline distribution of visitors & 167 & 154 & 136 & 125 & 69 \\
\hline ranks & 1 & 2 & 3 & 4 & 5 \\
\hline
\end{tabular}

Table 1. Continued.

\begin{tabular}{llllll}
\hline & Chess entertainment & Internet cafes or karaoke & working & drinking & gambling \\
\hline distribution of visitors & 52 & 43 & 37 & 19 \\
ranks & 6 & 7 & 8 & 9 \\
\hline
\end{tabular}

\subsection{Moral Relationships of Young Migrant Workers}

Moral relationships of young migrant workers, the averages from high to low are "mutual utilization", "indifference and barriers", "fraud", "irresponsibility", "care and help", "tolerance", "communication and understanding", "integrity" and "hostility", "responsibility"

Table 2 is the distribution of visitors and positions of moral human behaviors of young peasant workers. Most of them choose" mutual utilization" among 276 young migrant workers, the next are "indifference barriers", "fraud", "irresponsibility", "affection and assistance", "tolerance", "communication" and "integrity" "hostility", "irresponsibility". 
Above all, ranked in the top four in moral relations which are "mutual utilization" "cold barriers" "fraud" "irresponsibility"

are bad moral interpersonal relationships.

Table 2. Distribution of visitors and the ranks of young peasant workers' moral interpersonal relationships ( $N=276)$.

\begin{tabular}{llllll}
\hline & mutual utilization & indifference barriers & fraud & irresponsibility & care and help \\
\hline distribution of visitors & 160 & 130 & 97 & 97 & 95 \\
ranks & 1 & 2 & 3 & 4 & 5 \\
\hline
\end{tabular}

Table 2. Continued.

\begin{tabular}{llllll}
\hline & tolerance & communication & integrity & irresponsibility & responsibility \\
\hline distribution of visitors & 64 & 61 & 50 & 41 & 33 \\
ranks & 6 & 7 & 8 & 9 & 10 \\
\hline
\end{tabular}

\subsection{Young Peasant Workers' Leisure Life and Its Correlation Analysis of Moral Relationships}

In order to further explore what kind of leisure life of young migrant workers has significant relationships with morality interpersonal relationships, the researchers proceed double tail product-moment correlation to the leisure life and ethical relationships of 276 young peasant workers using SPSS16.0, the results of Pearson correlation are shown in table 3.

Table 3. Young peasant workers' leisure life condition and the coefficient of correlation of moral relationships (N=276).

\begin{tabular}{lllll}
\hline & Fitness & reading & tourism & drinking \\
\hline Affection & $0.125^{*}$ & $0.153^{*}$ & -0.046 & -0.077 \\
indifference & -0.088 & -0.066 & 0.089 & -0.031 \\
tolerance & $0.128^{*}$ & $0.126^{*}$ & -0.069 & 0.029 \\
irresponsibility & -0.103 & -0.048 & 0.047 & 0.100 \\
fraud & $-.0149^{*}$ & -0.048 & -0.029 & 0.048 \\
responsibility & 0.017 & 0.058 & $-0.133^{*}$ & -0.004 \\
hostility & 0.037 & $-0.121^{*}$ & -0.012 & 0.109 \\
integrity & 0.044 & 0.002 & -0.088 & 0.042 \\
mutual utilization & 0.002 & $-0.122^{*}$ & $0.214^{* *}$ & -0.042 \\
communication & 0.034 & 0.087 & -0.064 & 0.036 \\
\hline
\end{tabular}

Table 3. Continued.

\begin{tabular}{|c|c|c|c|c|c|}
\hline & Internet cafes or karaoke & gambling & Chess entertainment & art appreciation & working \\
\hline Affection & -0.059 & $-0.137 *$ & 0.002 & -0.013 & 0.051 \\
\hline indifference & -0.005 & 0.116 & -0.009 & -0.008 & -0.009 \\
\hline tolerance & 0.001 & -0.082 & -0.023 & 0.040 & -0.115 \\
\hline irresponsibility & -0.002 & 0.100 & -0.005 & -0.004 & 0.067 \\
\hline fraud & 0.060 & 0.070 & 0.072 & -0.092 & $0.156 * *$ \\
\hline responsibility & -0.004 & -0.056 & 0.079 & 0.019 & -0.014 \\
\hline hostility & 0.101 & 0.047 & 0.085 & -0.076 & -0.015 \\
\hline mutual utilization & 0.042 & -0.029 & $-0.134 *$ & 0.000 & -0.031 \\
\hline communication & -0.060 & -0.076 & -0.078 & 0.055 & -0.005 \\
\hline
\end{tabular}

Note: The data in the table above is the correlation coefficient, which is between 1 and +1. "-" stands for negative correlation between them, "+" means the relations are positively correlated. The relationships between the two have positive correlation. The absolute value of correlation coefficient is greater, it shows that the related degree is higher. "*" represents the significant coefficients. "*" means $\mathrm{p}<0.05$, the statistical significance is remarkable; "* $* "$ indicates $\mathrm{p}<0.01$, the statistical significance is extremely crucial.

In table 3, we find the following results are obvious:

First, "fitness" and "love" in the leisure life show the significantly positive correlation $(p<0.05)$, the correlation coefficient is 0.125 ; And "tolerance" has significant positive correlation with "fitness" $(\mathrm{p}<0.05)$, the correlation coefficient is 0.128. However, the "fitness" and "fraud" represent significantly negative correlation $(\mathrm{p}<0.05)$, the correlation coefficient is 0.149 . There is significantly and positively correlation between "fitness" and the good moral, significantly negative with bad morality interpersonal relationship. Namely, the leisure activities such as "fitness" of young migrant workers increase, "love" "tolerance" and other excellent moral relationships also will increase, while "fraud" and other bad moral relationships will reduce proportionally. In conclusion, increasing "fitness" leisure activities of young migrant workers is good to improve their good moral relationship and reduce their immoral human relations.

Second, "reading" and "love" is significantly positive correlation in the leisure life. $(\mathrm{p}<0.05)$, the correlation coefficient is 0.153 ; "tolerance" also has significantly positive correlation with "reading" $(p<0.05)$, the correlation coefficient is 0.126 ; In contrast, "fraud" shows the different result, $(\mathrm{p}<0.05)$. And the correlation coefficient is 0.149 . It's apparent that with the increase of "reading" leisure activities, "love" "tolerance" and other excellent moral relationships will increase eventually, and bad moral relationships such as 
"fraud" are less. Once increasing "reading" activity of young migrant workers, their good moral relationship will improve, their bad moral human relations also reduce.

Third, surprisingly "travel" has significantly negative correlation with "responsibility" ( $p<0.05)$, significant coefficient is 0.133 ; "mutual utilization" has significant positive correlation with "travel" ( $\mathrm{p}<0.05)$, the significant coefficient is 0.214 . With the increase of "tourism" leisure activities, "responsibility" and other excellent moral relationships decrease instead, "mutual utilization" and others will increase. The possible reasons are that there is a difference in the concept of "tourism" for young peasant workers. In further interviews, young migrant workers regard "tourism" as "wandering" "idleness" "doing nothing". This concept makes young migrant workers' "travel" leisure activities have negative correlations with some fine moral relationships such as "responsibility", and have significantly negative correlations with bad moral relations such as "mutual utilization".

Fourth, "drink" is negatively correlated with "mutual utilization" in leisure life $(\mathrm{p}<0.05)$, the correlation coefficient is 0.127 . With "drink" leisure activities increased, "mutual utilization" will decrease. Moderately increasing "drinking" in the young migrant workers leisure activities can reduce their bad moral human relations. In traditional Chinese culture, "drink" as an important way of interpersonal communication. For several young migrant workers, it is an crucial way of emotional communication and relaxation after hard work. They think that there is no utilitarian color when some workmates get together to drink carefreely, it could be the reason that "drink" leisure activities are negatively correlated with "mutual utilization".

Fifth, "gambling" this kind of leisure activity shows significantly negative correlation with "love" $(p<0.05)$, the correlation coefficient of 0.137 . It illustrates that once the "gambling" activities increase, young migrant workers' "love" will decrease.

Sixth, "continuing to work or make money" and "fraud" show significantly positive correlation $(p<0.05)$, the correlation coefficient is 0.156 ; Representing significantly negative correlation with "integrity" ( $<<0.05)$, the correlation coefficient is -0.130 . With the increase of "working", the bad moral relationships of young migrant workers such as "fraud" will increase, and "good faith" excellent morality interpersonal relationship will decrease. We conclude that depriving the leisure life of young migrant workers will lead to their moral deterioration of interpersonal relationships.

\section{Conclusion and Some Suggestions on the Promoting Moral Relationship of Youth Migrant Workers}

\subsection{Prolonging Young Peasant Workers' Leisure Time Help to Promote Their Good Moral Relationships}

Results show that depriving young peasant workers' leisure time to force them to work to make money, their "fraud" behavior will significantly increase, "integrity" behavior will significantly reduce. Properly improving youth leisure life conditions is benefit to promote their good ethical relationships, and then reduce the bad morality interpersonal relationships. Human ergonomics and labor psychology are consistent with mental load. Properly prolonging the time of young peasant workers' leisure life and recreating their psychological remaining resources are not only help to obtain their identification to work of individual and recognition to social work environment, but improve their moral human relations.

\subsection{Increasing "Fitness" and "Reading" Leisure Life Can Improve Excellent Moral Relationships of Young Migrant Workers}

The survey results indicate that "fitness" and "reading" are positively correlated with "love" and "tolerance" of young migrant workers, and they have significant negative correlation with "fraud". Increasing their "fitness" and "reading" can promote good moral relationship and reduce bad moral human relations. In the process of youth moral education and enlightenment, it's necessary for government to build some "reading spaces", increase the sports facilities, expand leisure activities such as "fitness" and "reading", these help young migrant workers resist bad moral relationships and improve good moral human relations.

\section{3. "Tourism" Should Not Be Used to Promote Moral Human Relations of Young Peasant Workers}

In the general opinion, people claim that "travel" can help people refresh themselves and promote mutual communication and help among people. But the survey results show that the "tourism" of the young migrant workers have significant negative correlation with "responsibility" and are significantly positively related to the "mutual utilization". As mentioned, the cause of this phenomenon has to do with the understanding differences to "tourism". This shows that people ought to use cautiously incentives such as the "tourism" in the ascension process of interpersonal relationships and do not use "tourism" to promote moral human relations of young peasant workers.

\subsection{Controlling "Gambling" and Other Recreational Activities and Improving Moral Interpersonal Communication of Young Migrant Workers}

The investigation results among the 276 young migrant workers, although only 19 people choose "gambling" as the main leisure activities, we can see "gambling" has significantly negative correlation with "love". "Gambling" increases, at the same time, "love", this fine morality interpersonal relationship has a significant reduction with "gambling". It is obvious that gambling is harm to moral human relations. In the leisure life activities of young migrant workers, we can strictly control "gambling" behavior, which helps to promote moral human relations of young peasant workers. 


\section{Fund Project}

(1) Anhui philosophy and social science planning project (AHSKQ2014D72)-The influence and countermeasures of the nihilism ideological trend of contemporary Chinese history on college students' ideological and political beliefs.

(2) The empirical study of life moral insight in rural middle school students project.

\section{References}

[1] Research Group of Research Office of the State Council. China's migrant workers study [M]. Beijing: Chinese yanshi press, 2006: 4.

[2] Pan Li. The promotion and development of moral health to mental health $[\mathrm{J}]$. Journal of contemporary youth research, 2010(2): 34-40.

[3] Shi Yajun \& Zhao Lingli. Citizens Humane Quality Survey in western China [M]. Beijing: China Renmin University Press, 2009: 29-36.

[4] Teng Han, Huang Honglei. The social integration of agricultural transfer population in the process of urbanization [J]. Jianghuai BBS, 2014, (01): 20-25.
[5] Zhang Hongyu, Teng Han. A study on the life adaptability of agricultural transfer population: a field study based on yangyang town, hefei city [J]. Journal of changchun university of technology (social science edition), 2015, 28 (03): 52-57.

[6] Teng Han, Huang Honglei. Changes in the moral consciousness of young farmers in the urbanization process -- take the county of anhui province as an example [J]. Urban problems, 2013, (12): 89-93.

[7] Ye Liangjun, Wang Qipei. Research on the identity of urban migrant workers - taking beilu street in Shanghai as an example [J]. Social work, 2013, (05): 75-80+105+153.

[8] Teng Han, Fang Ming. Attitudes of migrant workers towards science and their relationship with moral consciousness [J]. Journal of fuyang normal university (social science edition), 2012, (02): 24-27.

[9] Zeng Tianshan, Zhou Yue. Investigation and analysis of the learning needs of rural teenagers in China [J]. Education research, 2010, 31 (03): 29-36.

[10] Teng Han, Wang Baogen, Jiang Shuxiang. Investigation report on the moral behavior of farmers in China [J]. Journal of anhui agricultural university (social science edition), 2010, 19 (03): 10-13. 